\title{
Fabrication of Copper/reinforced Carbon Nanotube Bipolar Plate using Cold Spray Technique
}

\author{
Emmanuel Ajayi, Agrippa Hamweendo, and Ionel Botef
}

\begin{abstract}
This paper studies the possibility of using Cold Spray (CS) technique to fabricate Multi-Walled Carbon Nanotube (MWCNTs) re-enforced Copper $(\mathrm{Cu})$ bipolar plate for possible application in Fuel cells. Copper $(\mathrm{Cu})$ was chosen because of its excellent electrical and thermal conductivity, good tensile strength, and moderate corrosion resistance. On the other hand, MWCNTs were selected because of their extra-ordinary high mechanical strength, and electrical and thermal conductivity. In addition, as a carbon base product, MWCNTs are green compliant. Before deposition, the MWCNTs were dispersed in Copper $(\mathrm{Cu})$ using a planetary ball mill. Then, the mixture was sprayed using LowPressure Cold Spray System (LP-CS) at a temperature $400^{\circ} \mathrm{C}$ and air pressure $140 \mathrm{psi}(8.25 \mathrm{bar})$. The coatings were then characterized for microstructures using Scanning Electron Microscope and tested for electrical and thermal conductivity. The results of these experimental activities showed that the MWCNTs-Cu composite coatings deposited by LP-CS have enhanced thermal and electrical conductivity, and improve mechanical strength. This demonstrate that Cold Spray (CS) is a suitable technique for fabrication of MWCNTreinforced $\mathrm{Cu}$ bipolar plate for possible application in fuel cells.
\end{abstract}

Keywords - Cold Spray, Copper, Fuel cell, Metallic bipolar plate, Multi-Walled Carbon Nanotube, Planetary ball mill.

\section{INTRODUCTION}

$\mathrm{F}$ UEL cell technology already provides sufficient performance and durability to be competitive with alternative technologies in some applications such as for portable power, Auxiliary power unit (APUs), and in specialty applications such as material handling equipment. While in others, relative modest improvements are what is required.

The production costs of fuel cells need to be significantly reduced before the technology can gain commercial acceptance. The PEM fuel cell stack contains the membrane electrode assembly, bipolar plate, seal, and end plate. Among these components, the most costly and problematic to fabricate is the bipolar plate [1]. It account for over $80 \%$ of total weight and about $45 \%$ of the fuel cell stack costs [1]. They are primarily designed to perform multi-function tasks, such as distributing reactant gases uniformly to the gas diffusion layer (GDE), carry current from one cell to another, and preventing

*Corresponding author: Emmanuel Ajayi, With Department of Mechanical, Industrial, and Aeronautical Engineering \& also, Nanotech Laboratory, Dept. of Chemical and Metallurgy, University of The Witwatersrand, Johannesburg, South Africa leakage of reactants and coolant, and also, to remove heat from the active areas. [9]

Recent cost studies by Directed Technologies, Inc. (DTI) have projected the cost of Bipolar plate to be the largest single component of the cost of a PEMFC system at high volume production $(500,000$ stacks/year), with application of the bipolar plate accounting for 45 percent of the stack cost of $\$ 25 / \mathrm{Kw}$. [2]

Strategies are being pursued to help reduce costs and improve bipolar plate durability, by lowering precious Group Metal content through development of innovative Nanostructure materials. The use of Nano-composite material such as Carbon Nanotubes (CNTs) dispersed in Copper matrix is eminent in this research. Carbon Nanotube (CNTs) possesses extra-ordinary mechanical, electrical, thermal, and strong chemical properties. At individual level, this unique structure exhibit: $200 \times$ times the strength and $5 \times$ times the elasticity of steel; $5 \times$ times electrical conductivity, $15 \times$ times the thermal conductivity, and $1,000 \times$ mes current capacity of Copper; at almost half the density of Aluminum. As a carbon base product, CNTs have almost none of environmental physical degradation issues that is common to metals. [3]

Due to its density structure that is less than that of Aluminum, its dispersion in copper matrix is observed using mechanical alloying by planetary ball mill system before applying Cold Spray technique. The composite mixture passes through De-lava nozzle of the Cold spray machine unto a substrate for build-up. The experiment is carried out using certain parameters under different operating temperatures and pressure conditions. Each specimens under these variable conditions are then observed using Scanning Electron Microscope (S.E.M) to characterized the plate for uniform distribution as well as structural impacts. Also to test the plate for Thermal, Electrical conductivities, surface contact resistance, as well as Mechanical strength. The focus of this paper is to investigate the method of dispersion of CNT in $\mathrm{Cu}$ matrix using planetary ball mill system and to demonstrate Cold spray (CS) as new method for fabrication of Copper reinforced carbon nanotube bipolar plate. 


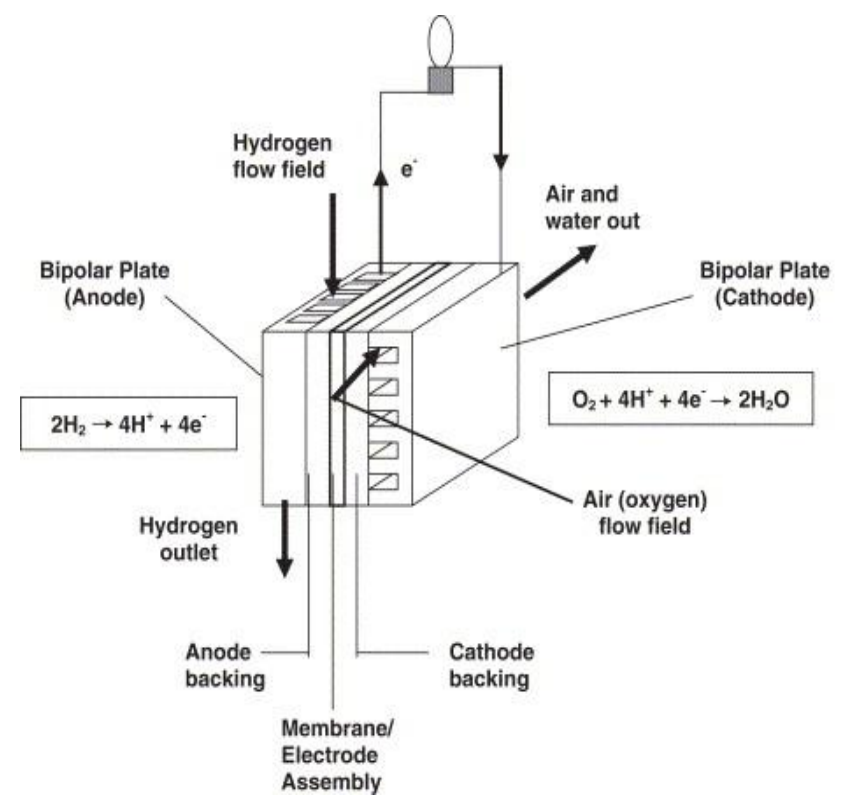

Fig. 1 Schematic diagram of PEM Fuel cell: Operating environments [4]

$\underline{\text { Primary functions of bipolar plates in PEM Fuel cell }}$

1. To supply reactant gases to the gas diffusion electrodes (GDE) via flow channel.

2. To provide electrical connections between the individual cells (Electrical conductivity)

3. It facilitate heat management (Thermal conductivity)

4. To separate individual cells in the fuel cell stack

5. To water management within the cell

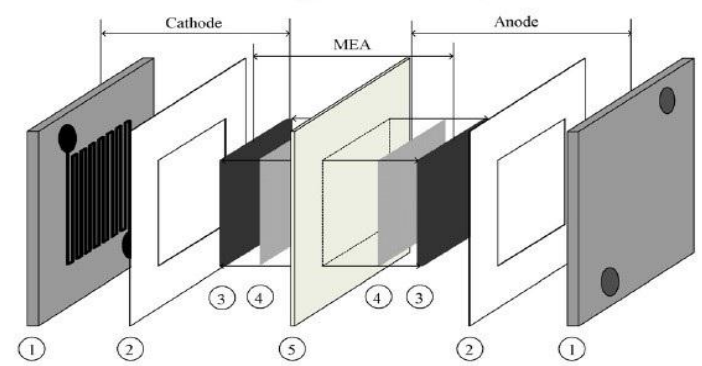

(1) Bipolar Plate (Gas Flow Channel)

(2) Gasket

(3) Gas Diffusion Laver

(4) Catalyst layer

(5) Polymer Electrolyte Membranc

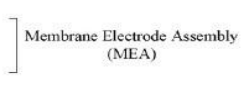

Fig. 2 A Simplified schematic diagram of a Proton exchange membrane fuel cell
TABLE I

PHYSICOCHEMICAL PROPERTIES OF BIPOLAR PLATE MATERIALS

\begin{tabular}{|l|l|}
\hline $\begin{array}{l}\text { Physical or chemical } \\
\text { properties }\end{array}$ & Functions \\
\hline $\begin{array}{l}\mathrm{H}_{2} \text { permeability (non- } \\
\text { porous plates }\end{array}$ & Distribution of fuel \\
\hline Electrical conductivity & $\begin{array}{l}\text { Lift current away from the } \\
\text { cell }\end{array}$ \\
\hline $\begin{array}{l}\text { Mechanical and } \\
\text { compressive strength }\end{array}$ & $\begin{array}{l}\text { Separated individual cell in } \\
\text { the stack }\end{array}$ \\
\hline Thermal conductivity & Facilitate heat management \\
\hline $\begin{array}{l}\text { Corrosion resistance, } \\
\text { bubble pressure (wet, } \\
\text { porous plate) }\end{array}$ & $\begin{array}{l}\text { Facilitate water } \\
\text { management within the cell } \\
\text { oxidants and residual gases } \\
\text { and liquids }\end{array}$ \\
\hline
\end{tabular}

\section{EXPERIMENTAL PROCEDURE}

\section{A. MATERIALS AND EQUIPMENT}

The use of Carbon nanotubes and Copper $(\mathrm{Cu})$ is eminent in this research work. Unless otherwise stated, Carbon nanotubes (CNTs) in the context of this paper is referred to Multi-walled carbon nanotubes (MWCNTs). Although different types of materials such as graphitic material and metals for bipolar plates of PEM fuel cells have been reviewed in the past. However, the benefits and limitations of these materials cannot be overlooked. Graphitic material has electrical conductivity but the conductivity of this composite is still below target. As reported by DuPont, the conductivity of a bipolar plate was 25-35 S/cm, while Lenssen et al [5] reported about $20 \mathrm{~S} / \mathrm{cm}$, which is below the target of $>100 \mathrm{~S} / \mathrm{cm}$ (or $0.01 \Omega \mathrm{Scm}^{2}$ ). Metals as bipolar plate material is usefully important especially in the vehicle industry. Metals offer lower weight and thickness of the plate and exhibit both thermal and electrical conductivities. E.g. the use of stainless steel is effective in its costs. Research investigation showed that the non-coated stainless steel have a problem of a surfaceinsulating layer [6]. So, a coating of chemically stable and electrically conductive film layer is highly needed before it can be used as bipolar plates. Hence, an innovative nanostructure material such as Multi-walled carbon nanotube (MWCNTS) is used as reinforced material with metal matrix (Copper) in this experiment to fabricate a bipolar plate. Consequently, the external morphology of material powder sample of CNTs was examined in Scanning electron microscope (SEM). A total of 6 optical micrographs at magnifications from $60 \times$ to $500 \times$ were analyzed using an image analysis software known as energy dispersive spectroscopy and electron dispersive X-ray (EDS and EDX) 


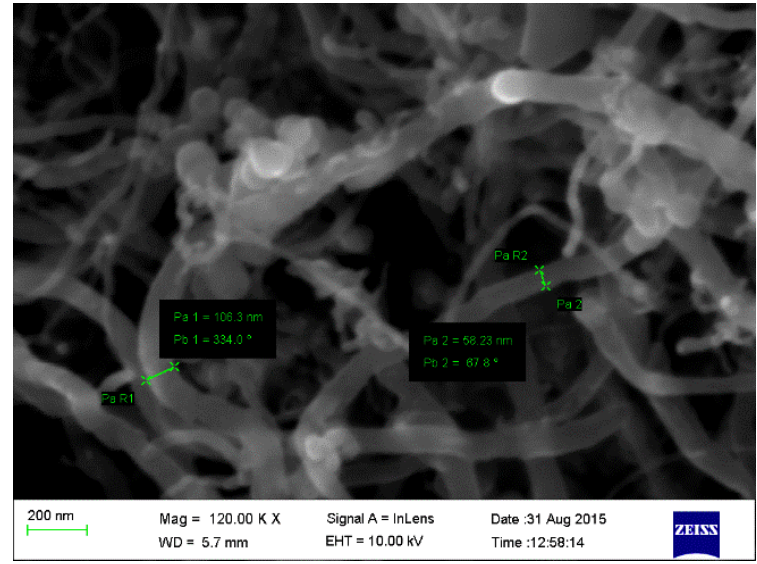

Fig 3a.

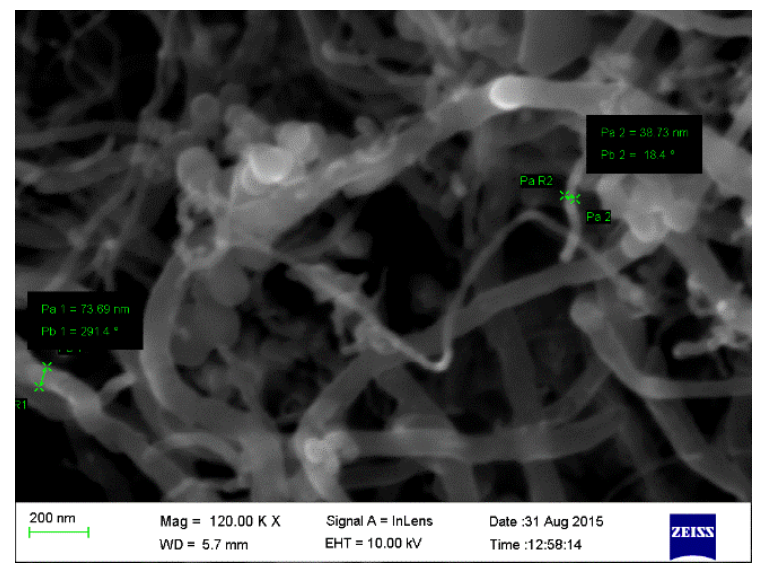

Fig 3b.

MWCNTs image from Scanning Electron Microscope

\section{B. DISPERSION}

In order to obtain homogeneous dispersion of carbon nanotube, a process called Chemical Vapor deposition was used to grow and produced a functionalized CNTs for this work. Although there are several challenges in the fabrication of metal matrix with carbon nanotubes reinforcement [7]. The most challenging part has been to obtain a uniform distribution of carbon Nanotubes in the matrix. They have large surface area up to $200 \mathrm{~m}^{2}$.g- ${ }^{1}$ and hence they tend to agglomerate and form clusters due to a force known as Van der Waals force. [12]

Moreover, the drying nature of carbon nanotubes to most molten metals can result in their clustering [6]. Good dispersion of the reinforcement is a necessity for the efficient use of the properties and for obtaining homogeneous properties. The second challenge is to ensure chemical and structural stability of the carbon nanotubes in the metal matrix. These challenges are put into consideration and so, the application of a new processing technique called "Planetary Ball milling" is introduced to ensure homogeneous properties and as well structural stability of CNT in the matrix. Copper $(\mathrm{Cu}-\mathrm{C} 5003)$ is used as the metal matrix in this project. The percentage ratio of Multi-walled Carbon nanotube (MWCNTs) to copper $(\mathrm{Cu})$ is prepared at different ratio parameters; $50 \%$
(MWCNTs): $50 \%(\mathrm{Cu}) ; 40 \%$ (MWCNTs): $60 \%(\mathrm{Cu}) ; 30 \%$ (MWCNTs): $70 \%(\mathrm{Cu})$ and 20\% (MWCNTs): $80 \%(\mathrm{Cu})$. The CNTs are mixed with $\mathrm{Cu}$ according to ratio proportion by means of Mechanical alloying using Planetary Ball mill system (as shown in Fig 5. below), to form a metal matrix composites in which centrifugal motion of jars with high accelerations of up to $20 \mathrm{G}$ is applied.

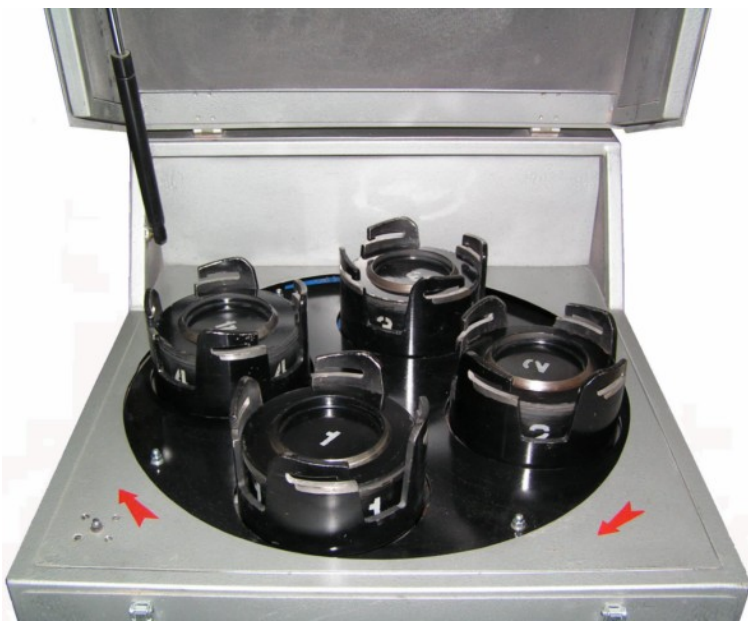

Fig. 4 Planetary Ball mill machine

Carbon nanotube is almost half the density of Aluminum according to Nanocomp Technologies, Inc (NTI). It typically have diameters ranging from $<1$ nanometer $(\mathrm{nm})$ up to $50 \mathrm{~nm}$. Efficient production of fine nanostructured powders requires the creation of technologies based on planetary mills. [16]

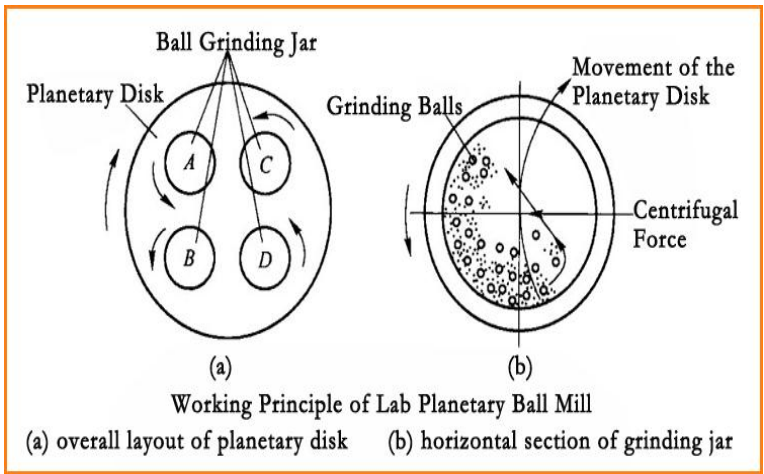

Fig. 5 Schematic image of planetary ball mill Machine

Planetary ball mill has four grinding jar holders installed on one planetary disk. When the disk rotates, the jar axis makes planetary movements and the balls in the jars grinds and mixes the samples in high speed movement. Material and milling bodies (usually balls) are loaded into the jars. The treated material particles (MWCNTs and $\mathrm{Cu}$ ) undergo multiple collision with grinding media and the jar walls. High velocity of moving milling bodies exerts high stress on the activated material. During this grinding, centrifugal motion of jars with high accelerations is applied. The metal matrix composite is milled down for 15 to 30 mins. 


\section{Principle scheme}
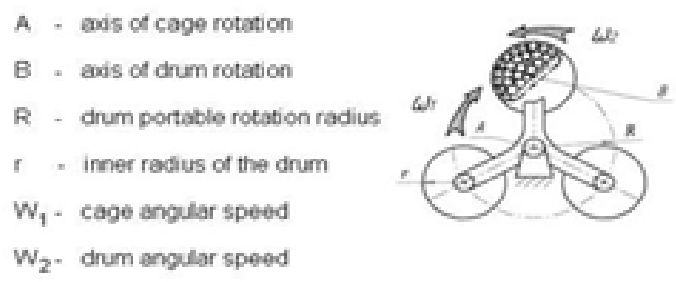

Fig. 6 Principle scheme of the planetary ball mill

TABLE II

TECHNICAL DATA OF PBM MACHINE

\begin{tabular}{|c|c|}
\hline Working Principle & impact and friction force \\
\hline Item No. & DECO-PBM-V-2L-B \\
\hline $\begin{array}{l}\text { Compatible Grinding } \\
\text { Jars }\end{array}$ & $(250 \mathrm{ml} 5500 \mathrm{ml}) * 4$ \\
\hline Max Feeding Capacity & $2 / 3$ capacity of the grinding jar \\
\hline Operation Mode & $\begin{array}{l}2 \text { or } 4 \text { grinding jars working } \\
\text { simultaneously }\end{array}$ \\
\hline Feeding Granularity* & $\begin{array}{l}\text { Soil materials }<10 \mathrm{~mm} \text {, others } \\
\text { materials }<3 \mathrm{~mm}\end{array}$ \\
\hline Discharging Granularity & down to $0.1 \mu \mathrm{m}$ \\
\hline Sample Type & $\begin{array}{l}\text { hard, medium-hard, soft, fibrous, } \\
\text { brittle, moist -dry o orr wet }\end{array}$ \\
\hline $\begin{array}{l}\text { Rotational Speed of } \\
\text { Grinding Jar }\end{array}$ & 800rpm \\
\hline $\begin{array}{l}\text { Rotational Speed Ratio } \\
\text { (planetary disk/jar) }\end{array}$ & $1: 2$ \\
\hline Drive Mode & gear drive and belt drive \\
\hline Speed Control & stepless speed regulation \\
\hline Electrical Details & $110 \mathrm{~V} / 220 \mathrm{VAC}, 50-60 \mathrm{~Hz}, 0.75 \mathrm{KW}$ \\
\hline $\begin{array}{l}\text { Max Continuous } \\
\text { Grinding Time (full- } \\
\text { load) }\end{array}$ & 72hours \\
\hline Weight & $75 \mathrm{KG}$ \\
\hline Dimension $(\mathrm{L} * \mathrm{~W} * \mathrm{H})$ & $720 * 468 * 535 \mathrm{~mm}$ \\
\hline Dia. of Planetary Disk & $340 \mathrm{~mm}$ \\
\hline
\end{tabular}

Courtesy of ACTIVE NANO, Inc.

After dispersion of the CNT-MMC through ball milling, the samples are then taking to Scanning Electron Microscope (SEM) for characterization, to test for uniform distribution of the carbon nanotubes in the metal matrix $\mathrm{Cu}$, to observe its homogeneous dispersion, and interfacial bond strength as shown in figs below.

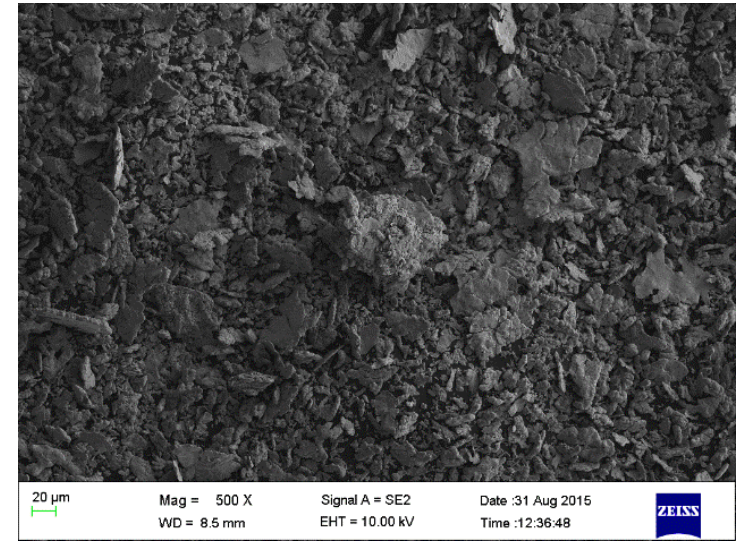

Fig. 7 CNT reinforced $\mathrm{Cu}$ composite under SEM

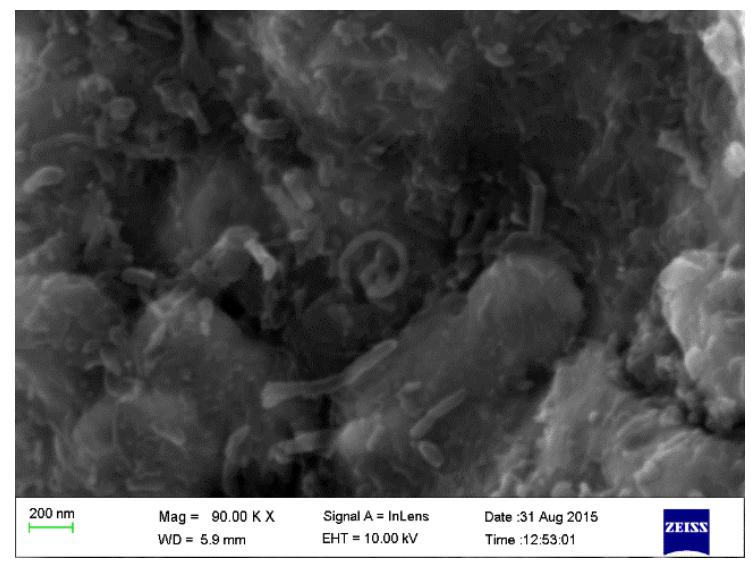

Fig. 8 CNTs reinforced $\mathrm{Cu}$ composite under SEM magnification $90.00 \mathrm{Kx}$

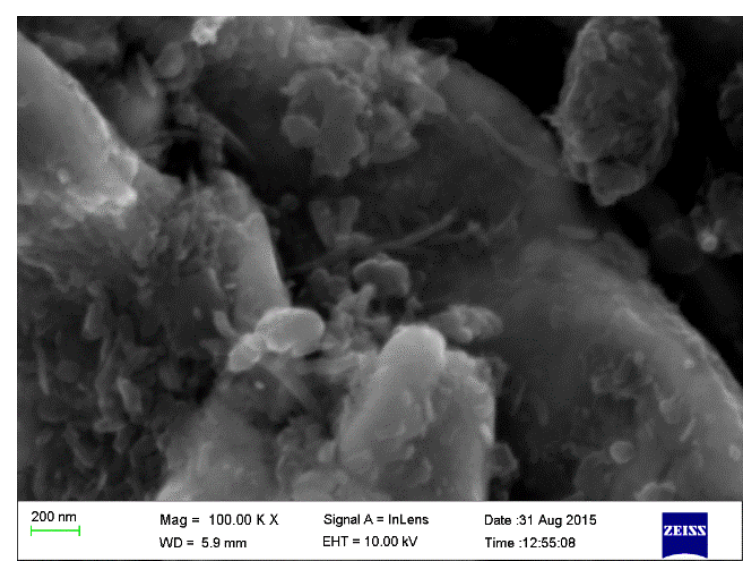

Fig. 9 CNTs-MMC image under S.E.M magnification 100Kx

\section{COLD SPRAY TECHNIQUE}

The use of Cold Spray as a technique to fabricate bipolar plate is adopted in this experiment due to its kinetic energy utilization rather than thermal energy for instant deposition. [10]. A cold spray system uses high-pressure gas system and Low-pressure gas system. But in this experimental set-up, a low-pressure system is used. It is smaller, easy-to-use, and portable. It is a process in which solid powder particles are accelerated over the sonic velocity through a De-Laval nozzle with a convergent-divergent geometry [15]. Powders are injected in the diverging section of the spray nozzle from a 
low-pressure gas supply. Low-pressure Cold spray (LPCS) systems are limited to $300-600 \mathrm{~ms}^{-1}$ particle velocities. They are used in the application of lighter materials and generally utilizes readily available air or nitrogen as gases. [10]

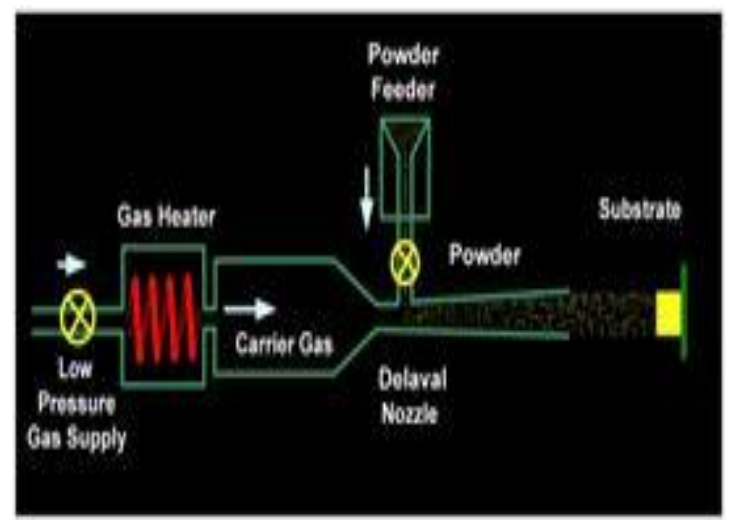

Fig. 10 Schematic diagram of low-pressure cold Spray system (LPCS)

In fig 10 above, air or nitrogen at relatively low pressure of $140 \mathrm{mPa}$ is pre-heated, up to $400^{\circ} \mathrm{C}$, then forced through the De-Laval nozzle. At the diverging side of the nozzle, the heated gas is accelerated to about $600 \mathrm{~m} / \mathrm{s}$. [14]. The CNTMM composites from the powder feeder is introduced downstream in the diverging section at feeding rate of $5 \mathrm{~kg} / \mathrm{h}$ and flow toward the substrate for a build up at spray distance of $15 \mathrm{~mm}$. These activities were carried out at three different parameter conditions of temperatures $300^{\circ} \mathrm{C}, 350^{\circ} \mathrm{C}$, and $400^{\circ} \mathrm{C}$ while other set-parameters such as the feed rate of 5 $\mathrm{kg} / \mathrm{h}$, Air pressure $140 \mathrm{mPa}$, and spray distance of $15 \mathrm{~mm}$ remain constant throughout the process.

The substrate used in this experimental activity is Solid metal Copper. A deposition of Aluminum A0050 powder was first carried out through the De-Laval nozzle of the cold spray chamber unto the solid metal copper substrate. This Aluminum deposition act as sub-substrate on the main substrate Copper. Aluminum A0050 is used because of its density structure and properties. The carbon nanotube reinforced Copper composites is then cold sprayed on the sub-substrate (aluminum) as a plate with surface area dimension $3 \mathrm{~mm} \times$ $3 \mathrm{~mm}$. However, the aluminum A0050 surface area dimension is designed to be larger. Hydrochloric acid (HCL) is used as leaching agent between the CNT-MMC and the main substrate, Solid metal Copper. Al A0050 dissolves fast in concentrated Hydrochloric acid, thereby leaving the CNTMMC bipolar plate and the solid Copper substrate separated. The hydrochloric acid is diluted so as not to react quickly on copper to form an oxide on its surface.

\section{RESULTS AND DISCUSSION}

From the experimental details, it was established that carbon nanotube homogeneously dispersed with copper C5003 powder by means of planetary ball mill method. The interfacial bond strength was observed under Scanning electron microscope (SEM) and a uniform distribution of carbon nanotubes in the matrix was obtained. Though a sequence of pores were formed at different conditions, but proper deposition of the copper reinforced carbon nanotube was realized. Moreover, the De-Laval nozzle on the cold spray machine was observed as the flow of the composites jets out of the nozzle for any apparent form of clogging in the nozzle due to the density of the CNTs material. However, no traces of clogging was found.

The copper reinforced carbon nanotube bipolar plate was also tested for its electrical conductivity using electrical conductivity meter (EC meter) measures in Siemens. The conductivity turned positive reading, which demonstrates that Cold spray technique is a valuable method for fabrication of Copper reinforced CNTs bipolar plate.

\section{REFERENCES}

[1] Cendi, H. Tsuchiya (Journal Power source, 2004

[2] M.C Williams, N. garland, URS Corporation and department of Energy, USA

[3] C.H Laurent, Nanocomp technologies, Inc. (NTI)

[4] Allen Hermann, Tapas Chaudhuri, Priscilla Spagnol. Int'l journal of Hydrogen Energy, 2003

[5] J. Lenssen, A. Heinzel, F Mahlendorf, University of Duisburg-Essen, Germany, Bipolar plates in Journal of Power source (Elsevier 2009)

[6] S.R Bakshi, V. Singh, Kantesh Balani, Scripta Materialia 59 (2008) 499-502 http://dx.doi.org/10.1016/j.scriptamat.2008.04.035

[7] Arvind Agarwal, Graham Mc Cartney, Sudipta Seal. Scripta Materialia 59 (2008), ScienceDirect

[8] Xianguo Li, Imran Sabir, Review of bipolar plates in PEM fuel cells, dept. of Mech. engineering, University of Waterloo, Ontario, Canada

[9] J. Moreira, A.L Ocampo, P.J Sebastian, M.A Smit, Int'l Journal of Hydrogen Energy (2003) http://dx.doi.org/10.1016/S0360-3199(02)00143-X

[10] J. Jaganathan Karthikeya. Cold Spray Process, thermal spray Technology

[11] H. Manjunathal, p. Dinesh. Fabrication and properties of dispersed CNTs-Al 6061 composites, Int'l Journal of innovative research in Science, Engr and Technology, 2013

[12] Erin Lynn Camponeschi, Dissertation on Dispersion and alignment of carbon nanotubes in polymer based composite, Georgia Institutes of Technology, 2007

[13] Muhammad Faizaan, Saden Zahiri, Syed H. Masood, Journal of Coatings, 2015

[14] A. Moridi, S.M Hassani-Gangaraj, M. Guagliano. Cold Spray coating: Review of material systems and future perspectives.

[15] Julio Villfuerte, Current trends in Cold Spray Technology: Looking at the future, CENTERLINE, WINDSOR, CANADA

[16] Andrey V. Petrov, Active Nano Technology Inc. (ATI) 